\title{
MedienPädagogik
}

$w w w$. medienpaed.com

Zeitschrift für

Theorie und Praxis

der Medienbildung

ISSN 1424-3636

Themenheft Nr. 19: Mobile Learning in Widening Contexts: Concepts and Cases

\section{A Case Study of Mobile Learning in Teacher Training - MENTOR ME (Mobile Enhanced Mentoring)}

\author{
Adele Cushing
}

\begin{abstract}
With announcements such as "more than half the world own a cell phone» (Lefkowitz, 2010) plus the convergence of multi-media elements in handsets, it is perhaps not surprising that education is calling for an increased use of mobile phones to support learning (Hartnell-Young \& Heym, 2008). Phone use will contribute to cost efficiencies by subsidising IT budgets (Yorston, 2010) and support personalised learning and students' underpinning knowledge. However, the reality is often «blanket bans) on mobiles in schools (Hartnell-Young \& Heym, 2008) due to teaching staff who are nervous of possible disruption and uncertain of pedagogic application. MENTOR ME (Mobile Enhanced Mentoring) was a pilot project with 20 teacher training students at Barnet College, North London. The limited time available to mentors and trainee teachers to engage in mentoring was solved by providing all students and mentors with email-activated mobile phones for ease of communication and support, facilitating situated learning (Naismith et al., 2004). Face-to-face meetings were partially replaced by capturing students' formal and informal learning with mobile functionality. This was shared with peers, tutors, mentors and lesson observers to further improve the mentoring and teaching experience. Self-reflection, peer assessment, peer support and ideasharing contributed to improving trainees' practice and employability. In addition, teachers' confidence and ability in using technology improved, particularly in supporting learning and underpinning knowledge. The success of this project has influenced the organisation to adopt mobile learning across the curriculum by facilitating student use of personal devices.
\end{abstract}

\section{Introduction}

The teacher training paradigm for Schools and Further Education (FE) in the UK is based upon social constructivist theory (Quality Improvement Agency, No date), co-operative and experiential learning, providing trainees with tasks and activities to underpin and reinforce knowledge. FE lecturers are encouraged to lead by example and disseminate role model delivery ideas to trainees. The increased ubiquity of mobile technology, its converging media of voice/video recording and internet access, has contributed to m-learning being ideally placed to facilitate 
personalised learning since a multimedia device can be customised to all user requirements (Traxler, 2010). Mobile learning is a new concept to many lecturers and is defined by its affiliation to mobile phones and gaming technologies as well as supporting learners on the move, i. e. in non-traditional learning environments (Sharples et al., 2009). In Barnet College, 20 teacher trainees and 7 mentors were provided with mobile phones to facilitate continuous communication and support, as well as enabling them to try mobile devices in classroom-based teaching and learning. This case study details background research surrounding mobile learning and describes the methods undertaken to evaluate practice within teacher training. Results come from both participants and devices, contributing to implications for practice. Discussion involving issues of continuity and sustainability leads to a conclusion of expectations for future practice.

\section{Background}

The Mobile Learning Network (MoLeNet - www.molenet.org.uk) has funded opportunities for the FE and the Skills Sector to engage in mobile learning through large and small-scale projects in the UK since 2006. Its work builds on research by Naismith et al. (2004), JISC (2005) and conferences such as Handheld Learning (http://www.learningwithoutfrontiers.com/). By allocating funding, providing project support with access to Mobile Mentors and setting up MoLeNet Academies they have enabled a functional community of mobile learning practice (see also Lave \& Wenger, 1991). Schools, too, have been involved in pilot projects, overseen by the local authority. The British Education Communication Technology Agency (BECTA) recommended gradual change for whole school adoption (Hartnell-Young \& Heym, 2008).

Barnet College is a large and highly successful North London Further Education college with around 12,000 students of all ages from 14 years upwards. Its programmes include courses categorised as ‘good) with «outstanding features by OFSTED inspectors. In 2010, staff and teacher trainees were funded by a small MoLeNet project and piloted the use of mobile devices, to assess their value for mentoring, communication and learning prior to moving into newly built premises. The aims of the project were established through conversations between the E-Learning and Teacher Training Managers. Naismith et al. (2004), as featured in Wishart's (2009) research into «Mobile Technology for Teacher Training», identify informal and lifelong learning and learning and teaching support as key features of mobile learning. The learner-centred mentoring project built upon these elements, encouraging reflection and critical thinking skills. Unlike Wishart's cohort, the teacher trainees were based and taught at Barnet College, only two students had teaching practice in alternative colleges. However, due to the College having dispersed sites, students encountered similar problems of mentoring support 
to those of Wishart et al. (2007) where internet enabled PDA's (personal digital assistants) were provided to bridge the communication gap encountered through dispersed geographical locations.

The primary objectives of the project were to:

- facilitate an efficient and effective mentoring process in teacher training

- improve communication between mentors and mentees

- introduce the concept of mobile learning to the teacher training curriculum,

- inspire trainees to adopt mobile learning pedagogy in their own teaching and learning delivery.

Full details can be found at www.molenet.org.uk/projects/southeast/barnet/.

\section{Methodology}

Twenty trainee teachers from a variety of subject areas, seven mentors and seven project leaders/support staff were provided with different types of smartphones (Samsung and HTC XDA) and iPhones. The iPhones were only given to the project leaders because phone calls could not be blocked and the project did not wish to incur additional costs to the 15GB data contract, supplied by $\mathrm{O} 2$ and pre-paid for 24 months. Participants in the project aged from 18 to 50 plus and possessed a range of IT capabilities from basic to advanced. It was hoped that all would engage in the project to support their personal methods of working.

Once the devices arrived there was a need for organisational support for system implementation; leadership from senior and curriculum management; curriculum peers; the Learning Centre and technical support. Project participants borrowed mobile devices from the Learning Centre and received technical support from its staff. The MoleNet community recommended that loan policies should state that if devices went missing the borrower should ensure that a crime number was obtained from police. It was also quickly identified that project participants must remember their PIN code for SIM locks, as blocked SIMs incurred an additional cost.

The trainees were introduced to mobile learning during a lecture prior to the distribution of devices. This provided an opportunity to educate them regarding the potential for their own practice and mentoring. The lesson during which phones were distributed hosted a round robin of activities including:

- setting up devices to receive college email and wireless connectivity

- demonstrating how the devices could be used for teaching and learning, e.g. YouTube clips, voice recording/filming work

- sharing captured work with others via email, Bluetooth or ActiveSync 
Mentors were also provided with similar support and training. In addition, the Learning Centres (Library Services) were involved in supporting individuals should they need further technical help.

Monthly reports were received during the project and support organised in response. The teacher training lecturer was instrumental in encouraging the sharing of good practice in weekly classroom experience and, as lesson observers, two of the project leaders also played key roles in promoting and demonstrating the use and potential of the devices in their own and others' practice.

Qualitative results were captured by telephone interview, observation and short emailed reports of user experience. Quantitative results were obtained by retention and achievement data as well as an online survey completed by a third of the project participants.

\section{Results}

\subsection{Trainee Teachers, Mentors and Project Leaders}

The round robin of activities gave all project participants an insight into how they could use the device. However, it was important to provide additional individual help through the Learning Centres as a point of reference for further help and support. Email-enabled mobiles provided trainees and mentors with an additional form of communication. Lesson observers were able to video, report and record via their devices, while reviewing work with trainees. Of the 20 students enrolled on the programme, two unfortunately left due to ill health but 100 per cent of retained students successfully progressed to Year 2 of the course. Traditionally these students work as full or part-time lecturers while training and time is at a premium. However, the majority of students engaged with the project and agreed it enhanced the mentoring process and their own teaching and learning practice. In comparison with Wishart's (2009) findings, trainees felt supported by personalised learning facilitated by the email capabilities of their devices as they were able to «keep in touch with email from my mentor and the College». Indeed, mentors and mentees regularly emailed, either from their phones or computers.

Flexible one-to-one support sessions were provided on a routine basis when the lecturer required it; however, fewer were required and time saved was re-invested into the course, providing students with regular high quality teaching and learning support experiences.

Of the 20 devices provided, only one student asked to change the model. This was in order to use it with his own SIM card and, as a motorcyclist, to Bluetooth the phone's radio to his helmet. His request was granted on the hypothesis that if he was using the phone for his social experience, he would be more likely to use it with his students. This was proved right since he became a key leader of 
mobile learning amongst his peer group. Some other trainees did not use the phones provided by the project, preferring to use their own due to capability and familiarity.

The pilot introduced the concept of mobile learning to the heart of the teacher training curriculum. Many trainees began using mobile devices with their own students. This immediately increased the uptake of mobile learning throughout the college. One lecturer commented that «students look after their phones more than they do paper based materials», emphasising the benefits of capturing class work through camera-phones (Image 1).

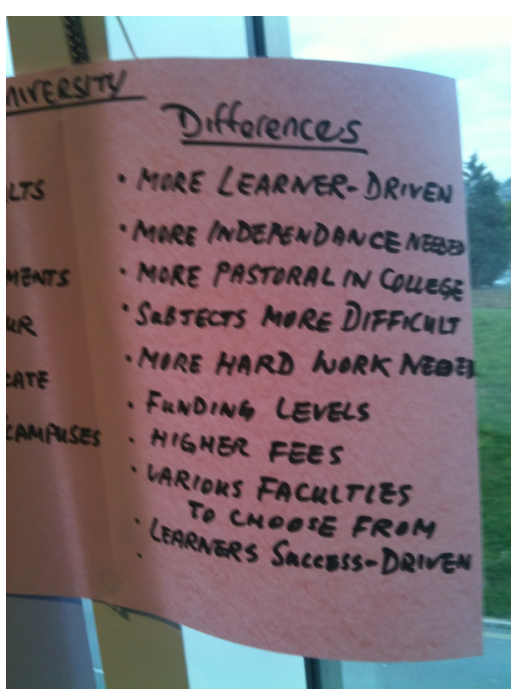

Image 1: Benefits of capturing class work through camera-phones

Indeed, prior to commencing the project, survey respondents indicated that phone and camera features were mainly used by participants, e-mail was least used. At the completion of the project, internet access had become the primary reason for use with email and camera usage a close second. All except one trainee had used their devices to communicate with their mentors, arranging meetings and accessing feedback. The individual who did not use this feature had easy access to their mentor in an office nearby.

One mentor did not have a device at the beginning of the project but the trainee captured voice/video recordings of issues they wanted to address with their mentor when they met.

Seventy-one per cent of teachers surveyed encouraged their students to use their own mobile devices for:

- searching for work placement locations

- providing evidence of their work

- taking voice notes about assignments or homework requirements

- presenting their work. 
Of seven survey respondents (Table 1) $100 \%$ said they would use a mobile device in the future to support their teaching, only one said they would not purchase a good quality mobile phone to use for teaching and learning. Respondents felt that phones were quicker to access at home or work (they do not take as long to load as computers) and they are easy to carry in a normal bag. The only reservation was the distraction of the internet for students in class but the same comment suggested appropriate research topics will keep learners on task.

Table 1: Mobile phone use for teaching

\begin{tabular}{|l|c|}
$\begin{array}{l}\text { Do you think you will use a mobile device in future, i.e. on your own to support your } \\
\text { work? }\end{array}$ \\
\hline Yes & 0 \\
\hline No & 7 \\
\hline $\begin{array}{l}\text { If yes, would you purchase a good quality mobile phone to use for teaching and lear- } \\
\text { ning? }\end{array}$ \\
\hline Yes & 6 \\
\hline No & 1 \\
\hline
\end{tabular}

The majority of project objectives were successfully achieved. In applying mobile devices to assessment pedagogy, trainees used the devices to video record their own lessons, self assess and discuss with their mentors. They photographed class/ whiteboard work (e.g. thought showers) and shared with students via the Virtual Learning Environment (VLE). Key discussions with students were recorded as well as assessments in the work placement. This in particular saved a large amount of time in travel and assessment and helped the student teacher to review points made during lessons and assessments. Curriculum Managers have endorsed this practice and it will continue in 2010/11.

Trainees using the devices increased their IT skills and persevered through ¿desirable difficulties〉 associated with learning and the use of new technologies. They discovered they could be creative with teaching delivery and facilitate their own students' use and learning beyond the confines of the classroom, increasing independent and situated learning. Class-based learners were able to research the internet on their mobiles in answer to questions and the completion of group tasks. This enhanced differentiation and contribution to class discussion. A greater number of teaching observations were facilitated through the use of video. Trainees activated video from the classroom so observers did not have to be in the room. The lead tutor was concerned that this process would not be rigorous enough but trainees were very positive as video provided a fair assessment, clearly showing good practice and areas for development. Trainees also felt less stressed 
by not having an observer in the room. This method contributed to approximately $f 10,000$ savings in observer time and travel costs.

Reflection and critical thinking skills were enhanced as trainees asked others to film them. They then watched themselves and identified elements of delivery that could be improved. They were able to reflect on their appearance, body and spoken language relating to teaching delivery and felt comfortable working this way. In the long term, enhanced reflection and critical thinking skills will enhance employability as students demonstrate self-improvement in their work.

Observers/Mentors captured critical reflections on teaching and learning through a voice recorder after observations. They also captured elements of good teaching practice and disseminated to staff via mobile email. A recent partner Higher Education Institute's (HEI) ¿Outstanding〉 UK Inspector's report states:

One of the partner colleges is making excellent use of emerging technologies to enhance mentoring support by exploiting iPhone technology to allow mentors to record conversations, photographs and video aspects of their work, thus enabling the instant sharing of good practice as it happens. (Ofsted, 2010a)

Model release forms are necessary for students (especially under 18s) having their image recorded for peer, self, formative or summative assessment. Images and video from college study should not appear on the internet and students should be assured that the use of media is for study/work only. This should be declared in the organisation's IT Acceptable Use Policy for the safeguarding of both students and staff.

\subsection{Devices}

Strong WiFi signal in an organisation may mean it is not necessary to invest in a data contract for devices. However, there were reports that the WiFi signal was particularly weak in some college buildings. Consequently it was useful to have the phones' GPS signal to access the internet as required. 15GB of data access may have been an over investment for this project but it was difficult to judge how much data students might download. Some trainees used Wi-Fi at home and college to minimise data contract use and only minor additional costs were incurred.

Multi-media elements converging in one device may mean that it becomes a rjack of all trades, master of nones, for example a camera feature may lack in picture quality compared to a specified digital camera. Voice recordings may also be faint and difficult to hear. The iPhone has good quality video and camera but the voice recording can be faint if not delivered through the speaker. Emailing the 
elements often means they get cut or (trimmed) if they are too large, perhaps losing essential content. The range of devices was chosen according to the practical requirements of the project. The smartphones were fit for purpose since they had Microsoft Office Mobile software and mentoring documents could be emailed between device/computer. The Samsung particularly was reported by Art and Design students to have a good camera. However, there remained a certain amount of «phone envys from participants who were not given an iPhone, believed initially to be caused by the marketing draw of Apple but this may also be due to the user friendliness of the device:

The teacher training lecturer (http://tinyurl.com/2fxcx2q) did not, prior to the project, own a mobile phone, which is surprising since

The idea of a single portable device that can make phone calls, take pictures, record audio and video, store data, music, and movies, and interact with the Internet — all of it — has become so interwoven into our lifestyles that it is now surprising to learn that someone does not carry one. (Horizon Report, 2009)

However, as a novice user the teacher trainer found the iPhone to be intuitive and particularly easy to navigate. The smartphones, by comparison, had iclunky) menus and needed a stylus to manipulate them. On reflection, further investment in iPhones could have been possible if savings had been made on the data contract. However, the use of iPhones and evaluation of apps for learning may not have given a real picture of student learning in college since iPhone handsets are comparatively expensive and, as a result, fewer teenagers own them.

On completion of the project some devices were returned for further loans, while others have been kept by practitioners. To date there have been no reports of stolen devices and only one has been damaged. One or two devices had accessories missing on return e.g. chargers, USB cables.

\subsection{Implications for Practice}

Qualitative feedback has provided many good examples of mobile learning practice for a variety of curriculum areas. These examples are largely due to the teacher training tutor leading by example. He states:

An indirect effect of having the iPhone has been that I can encourage students to use their phones, so I encouraged one class of numeracy students to photograph their own board work. Another student was so pleased with the pattern of colours created by his work in Maths (using counters for di- 
vision) that he wanted to use it for his art project so I encouraged him to photograph and e-mail it to his art teacher.

Other examples are:

- The voice recorder to interview a dyslexic student so he could submit a transcript of the interview as his essay. This, and other tools, enabled the student to pass the Level 5 course when he had previously not progressed from a Level 3 course. (http://www.moletv.org.uk/watch.aspx?v=CNKNW)

- The timer for classroom activities.

- The camera for photographing and sharing students' work.

- Live note taking during lesson observations.

His practice was commended by a partner HEl's UK Inspectorate report on subject leaders: "They are expert in using ICT to enliven their lessons and to enthuse learners.» (Ofsted, 2010a) And recorded key strengths as «the excellent use of ICT to support trainees' learning and classroom practice.»

Many trainees' teaching was observed using the devices, understanding the pedagogic potential of mobile devices and influencing cross-college practice. A co-observer was surprised as the teacher passed her mobile phone around asking students' opinion on a video but this way of teaching had become second nature to course participants. One art lecturer used his phone as a camera to project students work so they could evaluate and peer assess (see Image 2). They then took their own photos of work to keep long term.

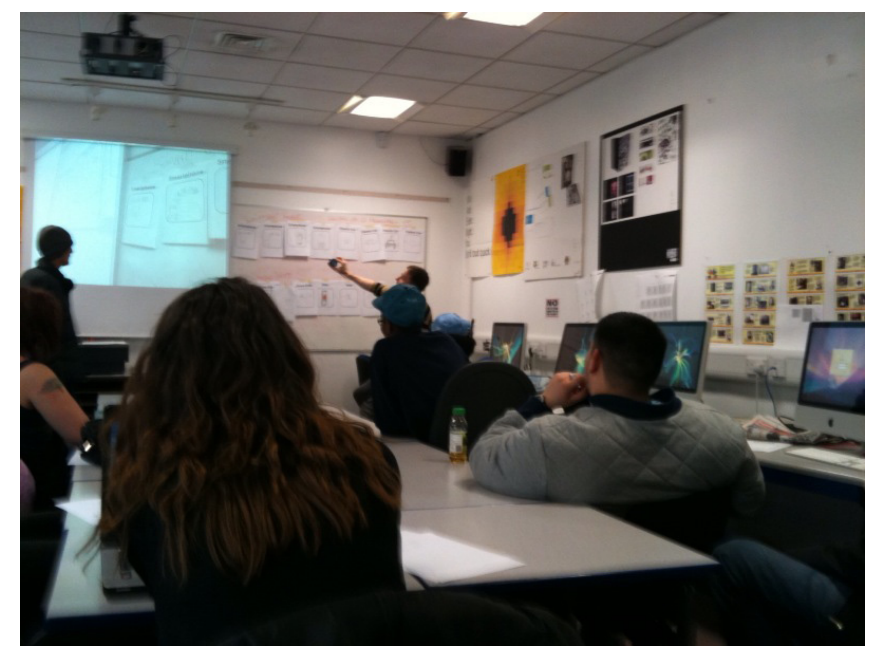

Image 2: Projecting student work 
In addition:

- A trainee teacher's student used her own phone to take pictures of a play area on work placement and this was shown in class. Students working with young people/children are aware that they must not take pictures of children in the play area.

- An English as Second/Other Language (ESOL) lecturer also used the phone's voice recorder to record students and analyse their pronunciation, enabling them to self-assess and improve.

- Vocational lecturers «used the camera \& video a great deal when observing students in practicals. We added the images to their assignments for evidence for their practical units.»

- 16-19 year old Mental Health students used their lecturers' mobile device to interview each other on their opinion of their course. This was easier than writing an evaluation. The video clips were also used to shown to their health care professionals (referrers) to evidence what students had been doing.

- Students borrowed lecturers' phones to take notes so they could email them to themselves.

- Mobile devices can plug the gaps of a low student:computer ratio or a power failure cutting off desktop access, further enabling classwork and group activities. However, battery power may be criticised since multi-media devices need increased charging when they are used for long periods of time.

The addition of mobile tools to learning has enhanced inclusion; expected cultural barriers have been broken as mobile phones are a socially inclusive method of communication. Students from all backgrounds have been observed capturing information digitally to refer to at a later date. Ubiquitous wireless access in an organisation also increases access to online resources and materials. Mobile devices are used to meet equality and diversity requirements; all project participants were loaned devices with some being used to meet specific needs e.g. dyslexia and visual impairment. http://www.moleshare.org.uk/case_studies.asp?ID=75

\section{Discussion}

The success of the project builds upon existing research in support of mobile devices being used appropriately to enhance teaching and learning. This is summarised in JISC's recent literature review on mobile learning (Belshaw, 2010). There is an expectation, particularly in Higher Education, that students wish «to use their own devices with corporately-owned IT infrastructure» (Belshaw, 2010, p. 6) and this is increasingly the case within Further Education. Indeed, in order to sustain personalisation of learning it is desirable that students use their own devices and, since the project challenged the organisation's stance on the use of 
mobile devices for learning, this is currently being facilitated. The student code of conduct has been changed at Barnet College to allow students to use mobiles for learning with permission of supervising staff. These devices should be silenced and will obviously not be used during examinations. Web 2.0 sites such as YouTube provide access to many formal and informal learning opportunities and access to these via a mobile contribute to personalised situated learning, facilitating a classroom without walls (Lepkowska, 2010).

However, challenges continue in terms of compatibility between hardware: "unhampered digital communication with peers, tutors and administrators» (Belshaw, 2010) is easier with wireless/internet-enabled devices. Students without data contracts may have difficulty in transferring data by USB from device to computer, depending on administrator privileges. Enabling Bluetooth can combat this but desktop PCs are often not Bluetooth-enabled.

Consideration has been given to e-safety, equality and culture in working with students aged 14 to 18. O2 have a web-filtering project called «Shield» (http:// www.o2.com/about/content_standards.asp) to safeguard young people in using the mobile internet and this has been applied to devices loaned to under 18s. Unfortunately, this system blocks sites more than it manages access as recommended by Ofsted (2010b). Wireless internet also minimises risk of accessing unsuitable sites since connections are via an organisation's filtered network. E-Safety should be integrated into the use of mobile devices for learning as it is with the use of other forms of ICT (Nightingale, 2010). It can be easier for students to cyber-bully through the use of texting but answering curriculum-related questions via text is also beneficial. The long term aim should be to educate students in the use of mobile devices for learning, keeping them busy, engaged and working together, thereby minimising cases of cyber-bullying. In a recent class the lecturer reported that students using their phones for note-taking were concentrating on the content and not distracted to check for SMS messages, consequently being less disruptive to the lecturer and others' learning.

Some mobile devices may need to be provided for students who do not own one. These students are in the minority but older students in particular are less likely to have a multi-media device. Improved WiFi access means less cost to individuals for internet access and SIM cards are not necessary to use the multimedia features. If devices are offered to students on long term loan they can use their own SIM cards to make the device fully functional with calls and texts. Blackberries are the device of choice for teenagers according to the Guardian (Smith, 2010) due to BBM (Blackberry Messenger), text bundles and a comparatively cheap handset. This has been proved in continuation projects with students aged 14-19. Students 
may also have text bundles, enabling them to participate in question and answer sessions via a TextWall (http://www.xlearn.co.uk/sms.htm) thereby enhancing the lower/higher order thinking skills described in Bloom's taxonomy.

\section{Conclusion}

This case study demonstrates the potential impact of small projects on a large organisation. The introduction of mobile devices for learning through the featured project sparked general interest across the college. Staff outside the project attended staff development sessions regarding mobile learning and have been considering how they can utilise their own students' mobile devices to support learning, whether that be timetable and deadline organisation through the calendar or capturing collaborative board work through the camera. Consideration has been given to implementation and student behaviour around mobiles. This behaviour appears to have improved by integrating their use into classroom practice, although there may be concern regarding student groups stealing devices from one another (Hartnell-Young \& Heym, 2008, p. 17). In order to be sustainable, mentoring with mobiles requires strong leadership and equal access to mobiles and their multimedia features. Projects continue with students' own devices and the leadership of lecturers will sustain success rates.

Students do not expect technology «to be used as a crutch for poor learning and teaching experiences» (Belshaw, 2010, p. 6). This project has proved the worth of mobile learning in and out of the classroom, for personalised and group support comparative with Wishart's (2009) research. However, findings also demonstrate that mobile devices are an additional tool for learning and should not be solely relied upon. Differentiated teaching methods remain important and lecturers should evaluate their own groups, i.e. behaviour management and access to devices before embarking on use of mobile learning with a whole class.

Curriculum development is another consideration as colleges prepare students for the commercial world. The prominence of IT businesses such as Intel, Apple, Microsoft is being replaced with those of Creative Digital and Information Technology (CDIT) businesses like Google, Amazon and Facebook, all of whom now have an efficient mobile presence. Consequently our students need to remain competitive with relevant skills in a changing work environment.

\section{Links}

Outputs on MoleTV http://www.moletv.org.uk/Default.aspx?module=AllMovies\&Org=67

Case Studies

http://moleshare.org.uk/search.asp?k=Barnet+College\&z=0\&s=0\&Page =1

Video evidencing - http://vimeo.com/11357181 
Voice recorder - http://vimeo.com/11357154

Camera to capture notes - http://vimeo.com/11357154

Qik - http://vimeo.com/11357154 (Log in with password: barn3t)

\section{References}

Atherton, James (2010). Learning and Teaching; Bloom's taxonomy [On-line] UK: Available: http://www.learningandteaching.info/learning/bloomtax.htm. Accessed: 10 November 2010.

Belshaw, Doug (2010). Mobile and Wireless Technologies Review [On-line] UK: Available: http://www.jiscinfonet.ac.uk/mobile/jisc-mobile-review.pdf. Accessed: 15 December 2010.

Hartnell-Young, Elizabeth; Heym, Nadja (2008). How mobiles help learning in secondary schools. Available: http://research.becta.org.uk/upload-dir/downloads /page_documents/research/Isri_report.pdf. Accessed 10 November 2010.

JISC (2005). Innovative Practice with e-Learning. A good practice guide to embedding mobile and wireless technologies into everyday practice. Available: http://www.jisc.ac.uk/uploaded_documents/publication_txt.pdf. Accessed 10 November 2010.

Horizon Report (2009). One year or less: Mobiles. Available: http://wp.nmc.org/ horizon2009/chapters/mobiles/. Accessed 16 December 2009.

Lave, Jean; Wenger, Etienne (1991). Situated Learning: Legitimate peripheralparticipation. Cambridge: University of Cambridge Press.

Lefkowitz, Jodi (2010). Joan Ganz Cooney Center Calls for New National Strategy to Invest in Mobile Learning and a Digital Teacher Corps. Available: http:// www.pearsonfoundation.org/pr/090109-cooneycenter.html. Accessed 10 November 2010.

Lepkowska, Dorothy (2010). Mobile learning for schools - a class without walls. Available: http://www.guardian.co.uk/resource/a-class-without-walls. Accessed 16 December 2010.

Naismith, Laura; Londsdale, Peter; Vavoula, Giasemi; Sharples, Mike (2004). Report 11: Literature review of mobile technologies in learning. Bristol: Futurelab. http://www.futurelab.org.uk/research/reviews/reviews_11_and12/11_01.htm. Accessed 12 November 2010.

Nightingale, Julie (2010). E-safety moves centre stage on school ICT agendas. Available: http://www.guardian.co.uk/resource/safety-moves-centre-stage. Accessed 16 December 2010.

Ofsted (2010a). Initial Teacher Education Inspection Report. Available: http://www. ofsted.gov.uk/oxedu_reports/download/(id)/121510/(as)/70119_346106.pdf. Accessed 11 October 2010. 
Ofsted (2010b). The safe use of new technologies. Available: http://www.ofsted. gov.uk/Ofsted-home/Publications-and-research/Browse-all-by/Documentsby-type/Thematic-reports/The-safe-use-of-new-technologies. Accessed 10 November 2010.

Quality Improvement Agency (no date). Using Moodle at Thanet College. Available: http://www.excellencegateway.org.uk/page.aspx?o=138102. Accessed 10 Nov 2010.

Sharples, Mike; Milrad, Marcelo; Arnedillo Sánchez, Inmaculada; Vavoula, Giasemi (2009). Mobile Learning: (Small devices, big Issues.) In Nicolas Balacheff, Sten Ludvigsen, Ton de Jong, Ard Lazonder \& Sally Barnes (eds.), Technology Enhanced Learning: Principles and Products. Heidelberg: Springer, pp. 233-249. Available at: http://www.lsri.nottingham.ac.uk/msh/Papers/KAL_Legacy_Mobile_Learning.pdf Accessed 29 December 2010.

Smith, Megan (2010). BlackBerry has become teenagers' smartphone of choice. Available: http://www.guardian.co.uk/technology/2010/aug/02/blackberryiphone-sales-technology. Accessed 10 November 2010.

Traxler, John (2010). Students and mobile devices. ALT-J 18 (2), pp. 149-160.

Wishart, Jocelyn (2009). "Use of Mobile Technology for Teacher Training.» In Mohammed Ally (ed.), Mobile Learning: Transforming the Delivery of Education and Training. Edmonton: AU Press, pp. 265-278.

http://www.aupress.ca/books/120155/ebook/13_Mohamed_Ally_2009-Article13.pdf. Accessed 29 December 2010.

Wishart, Jocelyn; Ramsden, Andy; McFarlane, Angela (2007). «PDAs and handhelds: ICT at your side and not in your face.» Technology, Pedagogy and Education 16 (1), pp. 95-110.

Yorston, Ian (2010). "Why Schools don't need ICT.» Report - October. ATL the education union, p. 24. Available at: http://www.atl.org.uk/publications-andresources/report/report-2010/feature-schools-ict.asp. Accessed 29 December 2010. 